This is the postprint of a paper published as:

Verstrynge, E., Wevers, M., Ghiassi, B., Lourenço, P. (2016). Debonding damage analysis in composite-masonry strengthening systems with polymer- and mortar-based matrix by means of the acoustic emission technique.

Smart Materials and Structures, 25, art.nr. 015009: 2016

Original Paper DOI: 10.1088/0964-1726/25/1/015009

\title{
Debonding damage analysis in composite-masonry strengthening systems with polymer- and mortar-based matrix by means of the acoustic emission technique
}

\author{
E. Verstrynge ${ }^{1}$, M. Wevers ${ }^{2}$, B. Ghiassi ${ }^{3}$ and P.B. Lourenço ${ }^{3}$ \\ ${ }^{1} \mathrm{KU}$ Leuven, Department of Civil Engineering, Building Materials and Building Technology Division, \\ Heverlee, Belgium \\ ${ }^{2} \mathrm{KU}$ Leuven, Department of Metallurgy and Materials Engineering, Heverlee, Belgium \\ ${ }^{3}$ ISISE, University of Minho, Department of Civil Engineering, Guimarães, Portugal
}

\begin{abstract}
Different types of strengthening systems, based on fiber reinforced materials, are under investigation for external strengthening of historic masonry structures. A full characterization of the bond behavior and of the short- and long-term failure mechanisms is crucial to ensure effective design, compatibility with the historic substrate and durability of the strengthening solution. Therein, nondestructive techniques are essential for bond characterization, durability assessment and on-site condition monitoring. In this paper, the Acoustic Emission (AE) technique is evaluated for debonding characterization and localization on Fiber Reinforced Polymer (FRP)- and Steel Reinforced Grout (SRG)strengthened clay bricks. Both types of strengthening systems are subjected to accelerated ageing tests under thermal cycles and to single-lap shear bond tests. During the reported experimental campaign, $\mathrm{AE}$ data from the accelerated ageing tests demonstrated the thermal incompatibility between brick and epoxy-bonded FRP composites and debonding damage was successfully detected, characterized and located. In addition, a qualitative comparison is made with digital image correlation and infrared thermography, in view of efficient on-site debonding detection.
\end{abstract}

\section{INTRODUCTION}

Fiber reinforced materials are frequently used as externally bonded reinforcement for structural enhancement of concrete and masonry structures [1-3]. They have well known advantages such as low weight to strength ratio and versatility in application. In recent years, composite materials such as fiber reinforced polymers (FRP) and steel reinforced grouts (SRG) have been under investigation for strengthening of historical masonry structures [4-6]. Thereby, fully characterizing the bond behavior and failure mechanisms and studying the compatibility with the masonry substrate are crucial to ensure effective design and durability of the strengthening solution [7]. Aspects such as failure initiation, interfacial damage propagation, damage localization and long-term bond quality are still under investigation. 
Compatibility between externally bonded strengthening system and the historic fabric is not only required with regard to durability of the bond, but also to enable re-treatability or limit the invasiveness of the intervention. This awareness, which is instigated by international guidelines such as the ICOMOS Iscarsah principles [8], has led to the investigation of inorganic matrices as a replacement for epoxybased adhesives [9]. The use of steel fibers with inorganic matrices (e.g. SRGs) adds compatibility to the above mentioned advantages of FRPs, providing new developments in durable strengthening of historical heritage and masonry structures.

Even though the focus has shifted towards the development of more compatible strengthening solutions, many past and present applications were/are being carried out with epoxy-based adhesives. Therefore, techniques are required for on-site condition assessment, monitoring and re-assessment of past applications.

In addressing these issues, non-destructive techniques are essential for the following tasks:

- Characterization of the debonding mechanisms, to evaluate the efficiency of the applied strengthening technique and to support numerical modeling (parameter estimation and validation);

- Durability and compatibility assessment of the strengthening system (long-term behavior);

- Detection, localization and quantification of inter-facial defects or progressive delamination for performance assessment, maintenance and early-warning systems (on-site monitoring).

In this paper, the effectiveness of the acoustic emission (AE) technique for debonding characterization and localization on FRP- and SRG-strengthened clay bricks is investigated. The bond degradation will be analyzed with the $A E$ technique during an accelerated ageing test under thermal cycles and during experimental shear bond tests. The different damage mechanisms that occur during a debonding process will be characterized and subsequent debonding areas will be located. To conclude this study, comparison with other NDT and suggestions for on-site debonding assessment are presented.

\section{DETECTION OF FRP DEBONDING}

\subsection{Characterization of debonding mechanisms}

Failure in FRP-strengthened masonry elements typically occurs due to FRP rupture or FRP debonding from the masonry substrate. Debonding in the masonry substrate, denoted as cohesive failure, occurs due to the lower mechanical properties of masonry compared to the repair material and the adhesive. Interfacial debonding, denoted as adhesive failure, normally occurs in case of poor surface preparation, e.g. when the surface is too smooth or wet upon application of the adhesive. It has been observed that environmental conditions, especially moist environments, can change the cohesive failure to adhesive failure [10]. The test program, partly described in this paper, also indicated that specimens subjected to accelerated ageing tests are more likely to show adhesive failure. Also a combination of cohesive and adhesive failure surfaces, denoted mixed failure mode, can occur. 
In case of strengthening with steel reinforced grout (SRG), in addition to masonry cohesive failure and adhesive debonding at the mortar-brick inter-face, debonding at the fiber-mortar interface can occur. The latter, being the most observed failure mode in the tests described in this paper, is followed by slipping of the fibers in the matrix. Typical failure modes are presented in Figure 1 for GFRP- and SRGstrengthened brick specimens.

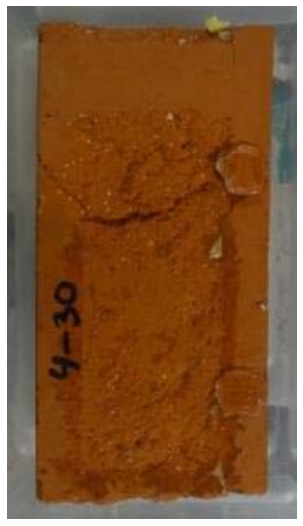

(a)

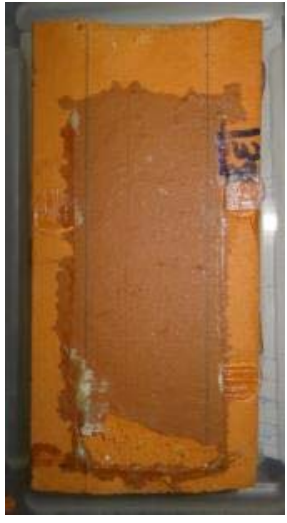

(b)

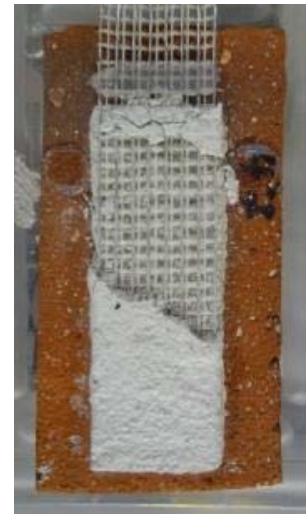

(c)

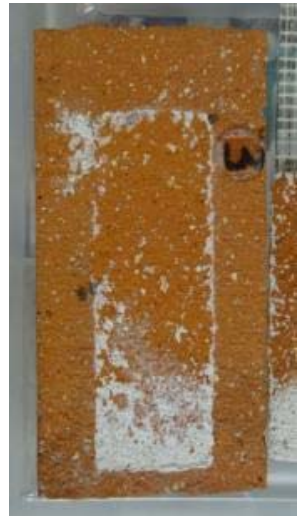

(d)

Figure 1. Observed failure modes in GFRP- and SRG-strengthened brick specimens: (a) cohesive failure; (b) adhesive failure; (c) steel fibers slipping and mortar cover separation; (d) mortar-brick interface debonding

\subsection{NDT for debonding detection}

Visual inspection and hammer tapping are the most widely used in-situ non-destructive testing methods for bond monitoring in FRP-strengthened elements, while several other methods are being applied such as digital image correlation (DIC) [11], infrared (IR) thermography [12], ultrasonic testing [13], shearography [14] and acoustic emission (AE) testing.

DIC and IR thermography were applied during previous bond tests on similar specimens and setups. DIC has been used during shear bond tests on GFRP- and SRG-strengthened bricks to obtain the evolution of strains on the FRP surface [15]. The use of active IR thermography for detection of interfacial flaws and FRP delamination induced by environmental ageing, with specimens similar to the ones used in this study, is reported in [16].

\subsection{FRP debonding detection with $A E$}

The acoustic emission ( $\mathrm{AE}$ ) technique has been extensively used for real time detection of internal damage propagation in structural materials [17-20]. In this technique, piezoelectric sensors are used to 
detect high-frequency mechanical waves produced from the release of strain energy during fracture and crack propagation. AE outputs are valuable in understanding crack propagation and failure mode in laboratory tests. The technique is also interesting for on-line structural health monitoring, especially during in-situ test loading of existing structures. For an introduction into the principles of $A E$ testing in civil engineering [21] and research on the application of this technique in masonry [22-24], the reader is referred to relevant literature.

Limited results are reported in the literature regarding the analysis of debonding phenomena in externally strengthened masonry and concrete components by means of the acoustic emission technique. AE monitoring during FRP debonding from concrete beams and slabs was studied by Carpinteri et al. [25] who detected the propagation of flexural cracks in an FRP-strengthened beam, and by Degala et al. [26] who observed the progressive debonding of CFRP strips from concrete slabs and differentiated between CFRP debonding and concrete failure (flexural, compressive or shear failure) by looking at the relative intensity of the AE signals. Shear behavior of strengthened masonry walls was analyzed with the acoustic emission technique by Masera et al. [27] who observed decrease of the signal peak frequency upon failure of the masonry specimens. In the presented study, the debonding mechanism itself will be the object of investigation by means of the acoustic emission technique.

\section{EXPERIMENTAL PROGRAM}

The experimental study focuses on the detection of debonding with the AE technique during an accelerated ageing test under thermal fluctuations and during laboratory shear bond tests on two types of strengthening systems. Clay bricks were strengthened with Glass Fiber Reinforced Polymer (GFRP) and with Steel Reinforced Grout (SRG). Twelve single-lap shear bond tests were performed with AE detection, being three reference specimens and three aged specimens for each strengthening type.

\subsection{Materials and test specimens}

Test specimens consisted of single bricks strengthened with GFRP and SRG composites. Solid clay bricks with dimensions of $200 \times 100 \times 50 \mathrm{~mm}$ were used as substrate. The composite materials were cut in 50 $\mathrm{mm}$ width and applied to the bricks' surface along $150 \mathrm{~mm}$ length of the brick with a $40 \mathrm{~mm}$ unbonded part near the loaded end. GFRP strips were applied to the bricks' surfaces following the wet lay-up procedure. A two-part epoxy primer was applied for preparation of the substrate and a two-part epoxy resin was used as matrix for the GFRP.

For SRG-strengthened brick specimens, a 1-directional medium density steel fiber net was used as reinforcement. The steel fibers were placed on a $3 \mathrm{~mm}$ thick layer of a lime-based mortar that was applied on the sand-blasted brick's surface. Then, an-other $3 \mathrm{~mm}$ mortar layer was applied to cover the steel fibers. Mechanical properties of the bricks and strengthening materials are presented in Table 1 as the mean value of five tests and the coefficients of variation (CoV). 
Table 1. Mechanical properties of strengthening material and bricks.

\begin{tabular}{llcc}
\hline Masonry brick & & Mean value & CoV (\%) \\
\hline Compressive strength & $f_{\mathrm{cb}}(\mathrm{MPa})$ & 14.2 & 15.7 \\
Flex. tensile strength & $f_{\mathrm{tb}}(\mathrm{MPa})$ & 1.6 & 24.6 \\
\hline GFRP strips & & & \\
\hline Tensile strength & $f_{\mathrm{tf}}(\mathrm{MPa})$ & 1250 & 15.0 \\
Elastic modulus & $E_{\mathrm{f}}(\mathrm{GPa})$ & 75.0 & 8.2 \\
Ultimate deformation & $\varepsilon(\%)$ & 3.0 & 20.2 \\
\hline Epoxy resin & & & \\
\hline Tensile strength & $f_{\mathrm{tm}}(\mathrm{MPa})$ & 53.8 & 9.7 \\
Elastic modulus & $E_{\mathrm{m}}(\mathrm{GPa})$ & 2.5 & 9.5 \\
\hline Primer & & & \\
\hline Tensile strength & $f_{\mathrm{tm}}(\mathrm{MPa})$ & 51.4 & 11.1 \\
Elastic modulus & $E_{\mathrm{m}}(\mathrm{GPa})$ & 2.4 & 6.1 \\
\hline Mortar & & & \\
\hline Compressive strength & $f_{\mathrm{cm}}(\mathrm{MPa})$ & 12.7 & 10.1 \\
\hline Steel fibers & & & \\
\hline Tensile strength & $f_{\mathrm{ts}}(\mathrm{MPa})$ & 2980 & 2.9 \\
\hline
\end{tabular}

\subsection{Experimental setup}

Accelerated ageing tests

To investigate the effect of environmental exposure, the specimens were exposed to 180 temperature cycles in a climatic chamber. In each cycle, the temperature was kept constant at $+10^{\circ} \mathrm{C}$ for $2 \mathrm{~h}$. It was then increased to $+50^{\circ} \mathrm{C}$ in $1 \mathrm{~h}$, followed by $2 \mathrm{~h}$ constant temperature at $+50^{\circ} \mathrm{C}$. Then, the temperature was decreased again to $+10^{\circ} \mathrm{C}$ in $1 \mathrm{~h}$, resulting in $6 \mathrm{~h}$ cycles of exposure.

During the accelerated ageing process, $A E$ hits were monitored on four specimens using a 4-channel Vallen AMSY-5 system with $150-500 \mathrm{kHz}$ operation frequency and $5 \mathrm{MHz}$ sampling rate. Four $150 \mathrm{kHz}$ resonance sensors were attached to the middle of the side of a brick by means of hot melt glue, which was chosen to resist temperatures of $50^{\circ} \mathrm{C}$ without softening. The preamplifier gain was set to $34 \mathrm{~dB}$ with a fixed threshold level of $50 \mathrm{~dB}$. To calculate the $A E$ energy, the $A E$ signal is squared and integrated and the energy unit (eu) is given by $1 \mathrm{eu}=10-14 \mathrm{~V}^{2} \mathrm{~s}$.

Shear bond tests

Single-lap shear bond tests were performed using a closed-loop servo-controlled testing machine with maximum load capacity of $50 \mathrm{kN}$. A rigid supporting steel frame was used to support the specimens and avoid misalignments in the load application. The specimens were pulled monotonically with a speed rate of $5 \mu \mathrm{m} / \mathrm{sec}$ under displacement control and the resulting load was measured by means of a load cell. 
The relative slip between the composite material and the brick was measured with two LVDTs glued at the loaded end and one LVDT glued at the free end. Four $150 \mathrm{kHz}$ resonance AE sensors were attached two by two on opposite sides of the bricks, see Figure 2.

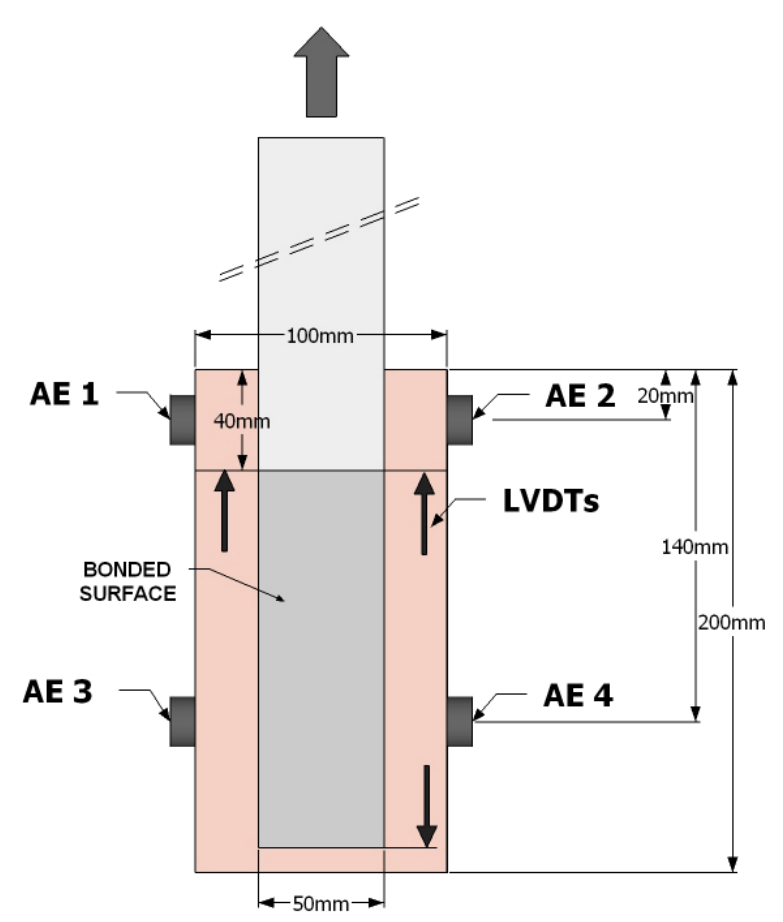

Figure 2. Single-lap shear bond test: test instrumentation and specimen dimensions.

To locate the AE sources in real time, a standard planar location algorithm is applied (Vallen Systeme $\mathrm{GmbH}, 2004)$. This algorithm assumes isotropic and homogeneous velocity of wave propagation and iterates until a minimum location error is obtained. Needed input for AE source location estimation are the wave velocity, the sensor locations and the arrival time difference of the AE event at the different sensors. Setting the correct wave velocity is particularly difficult for the setup at hand, since the limited size of the specimens causes reflections and boundary effects and the mechanical properties of the involved materials, and thus the wave velocities, are not fully isotropic. In addition, the setup is in fact 3D (AE sensors are placed on the side of the specimen while cracks occur towards the front surface), while a planar sensor setup and location algorithm are applied; the wavelength is equal to the velocity/frequency ratio (approximately $1000 \mathrm{~m} / \mathrm{s} / 150-500 \mathrm{kHz}=2-7 \mathrm{~mm}$ ) and poses a lower limit for the location accuracy; Crack formation during the test will increase the heterogeneity of the specimen and hinder source location towards the end of the test.

Some of these issues can be solved by applying more advanced location algorithms and more accurate arrival time determination. Since the location accuracy is not the main focus of the present research, a pragmatic approach was followed for the calibration. A grid $(20 \times 30 \mathrm{~mm})$ is drawn on the back of the 
bricks and the wave velocity in each specimen is determined by searching for the minimum average source location error, by means of pencil lead breaks before the test. This resulted in an average location error limited to $12 \mathrm{~mm}$ in the middle area of the bricks and a location error between 5-17 mm for the middle point of the grid. This latter point has equal distance to all sensors, a large error at this location thus indicates a non-homogeneous specimen or a non-exact positioning of the AE sensors.

\section{RESULTS AND DISCUSSION}

\subsection{Damage detection during environmental ageing}

Damage progress was monitored by means of acoustic emission detection on two SRG- and two GFRPstrengthened bricks. The average number of $A E$ hits per day recorded for each specimen within a period of 45 days is presented in Figure 3. Limited AE activity is recorded for each type of specimen and, as a first observation, it can be mentioned that not much difference is observed between the SRG- and GFRPstrengthened specimens.

When the moments of $A E$ energy emission are compared for both types of specimen, an important difference is observed. AE emissions in the SRG-strengthened specimens occur randomly, while for the GFRP-strengthened bricks, the majority of AE energy is emitted during temperature decrease (Figure 4). This is an indication of the different damage sources. The AE hits which are detected from SRGstrengthened specimens probably originate from the further hardening, shrinking or cracking of mortar. In the GFRP-strengthened bricks, the AE output during temperature decrease is a manifestation of the thermal incompatibility between the epoxy glue and the brick. Since the thermal expansion coefficient of epoxy can be up to 10 times larger compared to brick, the temperature cycling causes stress concentrations which might lead to damage propagation at the brick-GFRP interface. 


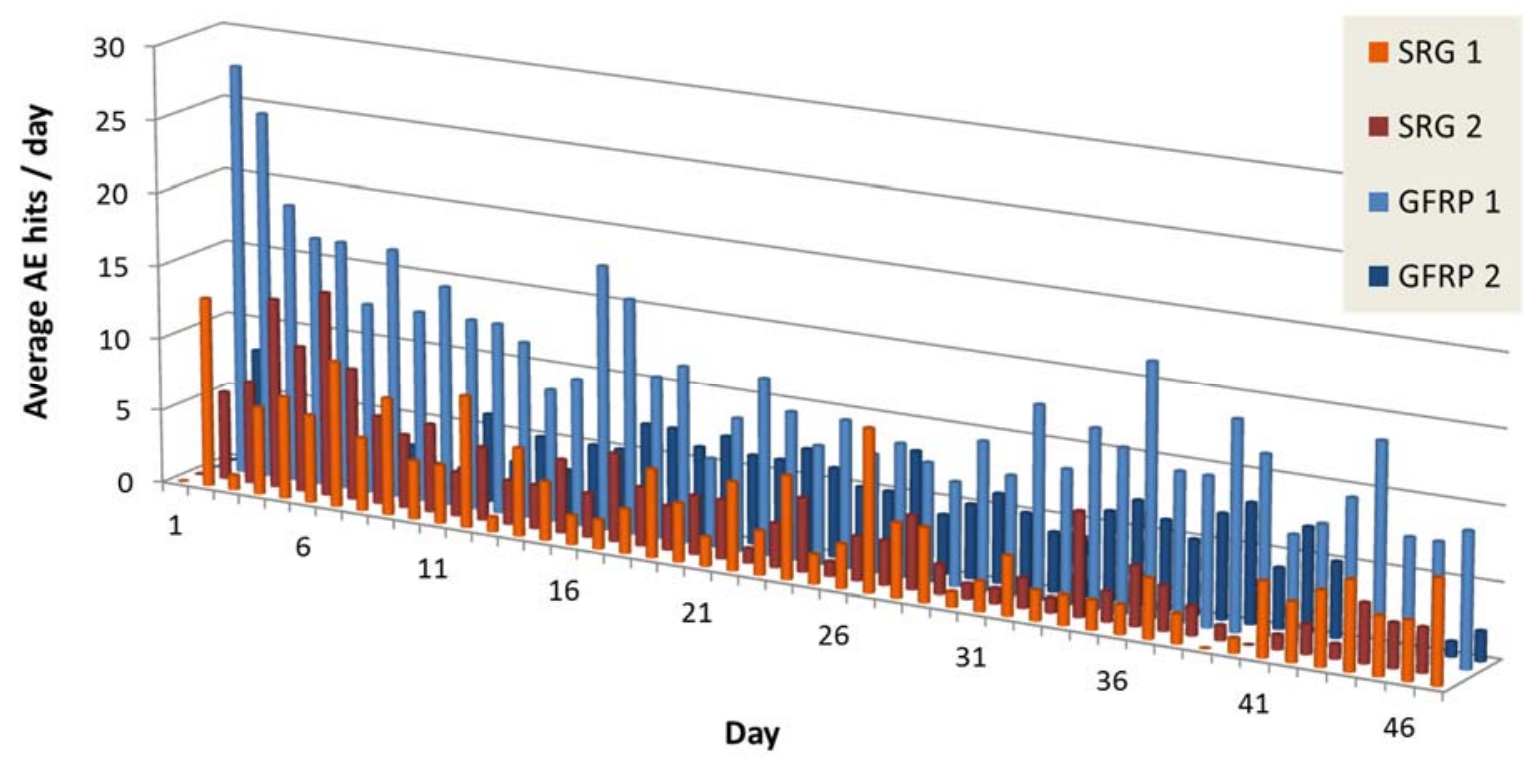

Figure 3. Average number of AE hits per day, recorded on 2 SRG-strengthened and 2 GFRP-strengthened specimens during environmental ageing test.
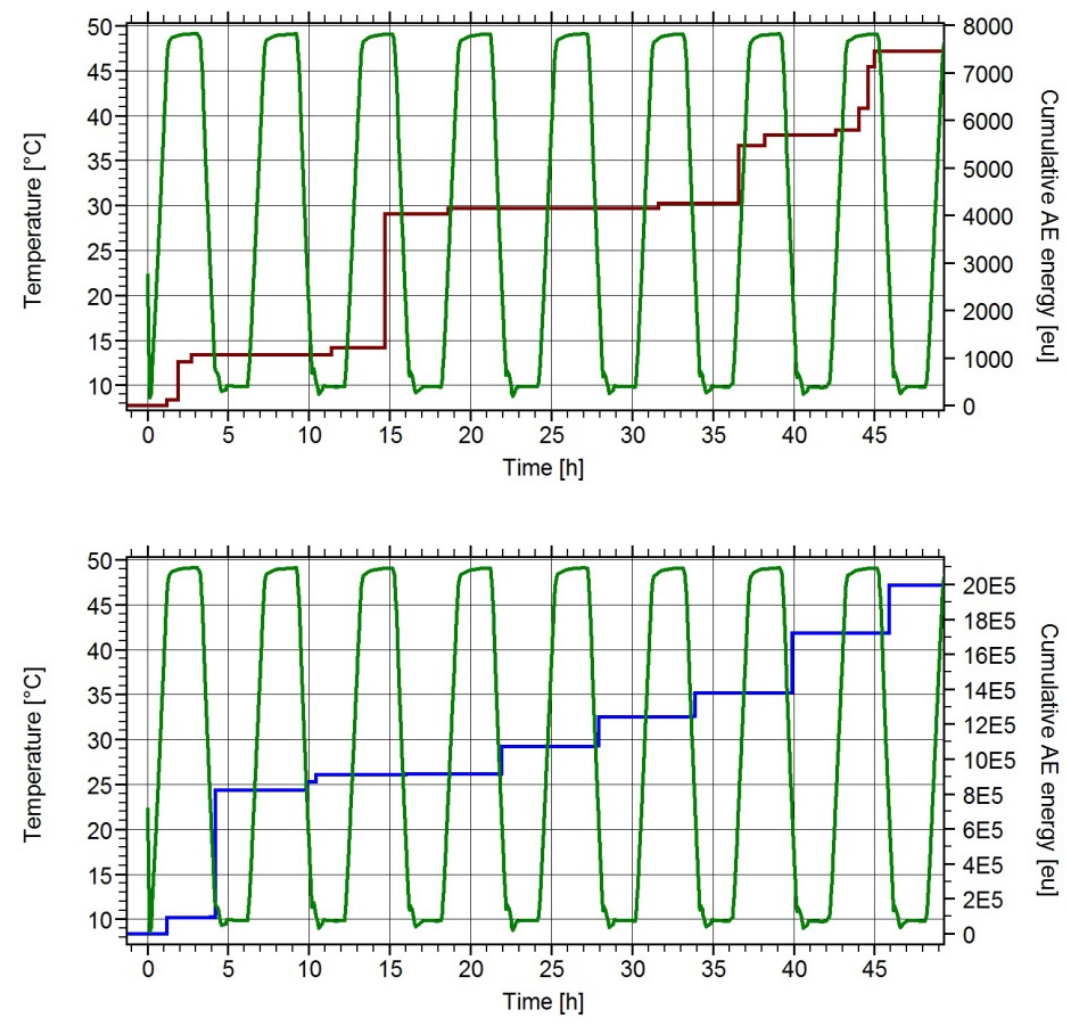

Figure 4. SRG-strengthened specimen: typical temperature fluctuation and random emission of AE energy (above); GFRP-strengthened specimen: typical temperature fluctuation and periodically emitted $A E$ energy (below). 


\subsection{Damage detection during shear bond tests}

Typical AE results obtained from the debonding tests on GFRP-strengthened brick specimens are presented in Figures 5-6. The results in Figure 5 are presented for a specimen with mixed cohesive/adhesive failure mode, in terms of cumulative AE energy and slip development during the test. Generally, the debonding phenomenon can be divided into three main regions: elastic range, microcracking range, macro-cracking and progressive fracture. In the elastic range, the system deforms without any crack generation or AE activity. The small displacement measured at this stage is due to the elastic deformation of the FRP composite. As the applied force increases, micro-cracks appear in the interfacial region and they can be distinguished by initiation of AE activity with low emitted energies. As the debonding progresses, macro-cracks are formed and propagate along the interface with higher fracture energy being released. The cumulative AE energy increases with a stepwise pattern in which each sudden jump can be attributed to macro-fracture events. A sudden release of AE energy is also observed at the moment of full debonding at the end of the test. The cumulative AE energy could thus be applied to define the subsequent regions of fracture progress.

The effect of failure mode on the AE outputs is investigated in Figure 6. A clear distinction is found between $A E$ outputs of specimens with different failure modes. In the specimen with cohesive debonding, the $A E$ energy release remains relatively low throughout the test, accompanied by a sudden and large amount of AE energy release when debonding occurs at the end of the test. The observed behavior confirms the brittle and sudden nature of the cohesive debonding. In the specimen with cohesive/adhesive failure, a progressive release of energy is observed during the test. In the specimen with adhesive debonding mode, progressive detection of AE energies is observed until complete debonding. However, the magnitude of the detected energies is much lower than the ones detected in the specimens with cohesive failure mode, due to the different nature and fracture properties of brick and FRP/brick interface.

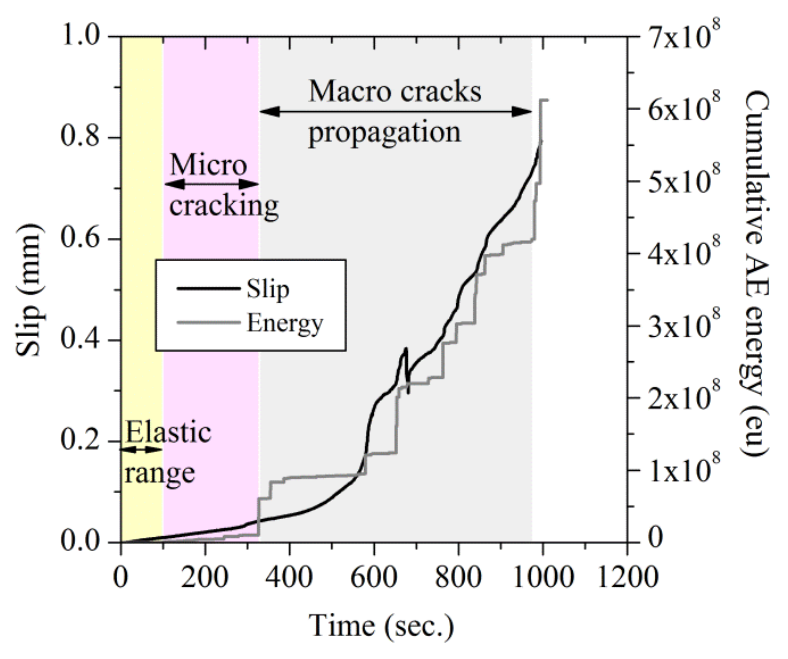

Figure 5. Typical AE results in a GFRP-strengthened brick specimen with cohesive/ adhesive failure mode: evolution of slip and cumulative AE energy 


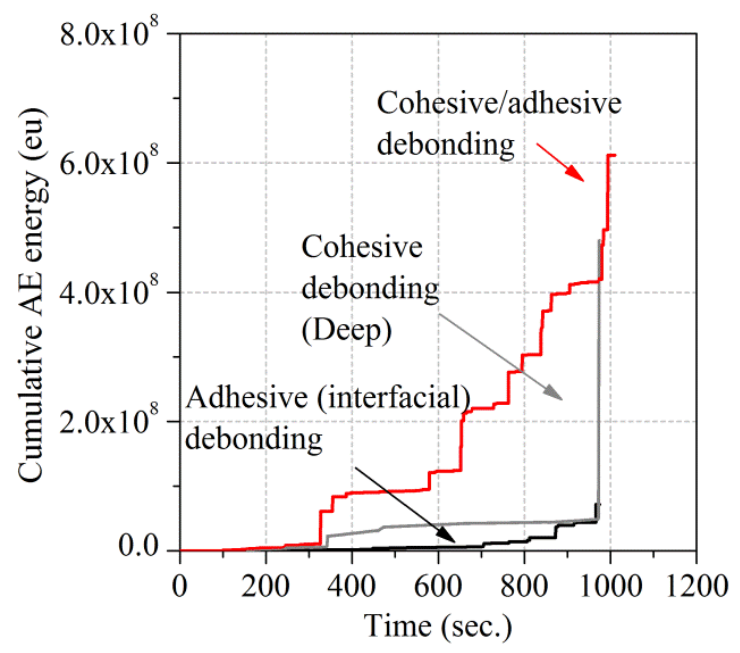

Figure 6. Comparison of AE output for different failure modes in GFRP-strengthened bricks

Figure 7 presents a typical result obtained from an SRG-strengthened brick specimen, which failed with slipping of the steel fibers and mortar cover separation. Mainly, three regions representing different mechanisms can be observed during the debonding process. AE activities before the first cracking of the mortar are negligible. During the mortar cracking, the rate of AE activities increases and high AE energy is detected as the force increases. The resisting mechanisms in this region are adhesive bond and friction between the steel fiber and mortar. Detachment of the bond is accompanied by releasing relatively high fracture energies, observed as sudden jumps in the AE cumulative energy curve. As the debonding progresses, the bond diminishes and friction governs the failure mechanism resulting in a reduction of the detected AE energy rate. The debonding occurs with a sudden force reduction and slip increase. In contrary to the GFRP-strengthened specimens, no direct relation can be observed between the measured slip and AE cumulative energy.

In Figure 8, a comparison is made between two SRG-strengthened specimens with different failure modes, namely brick/mortar detachment and fibers slipping. A brittle behavior is observed in the specimen with brick/mortar detachment failure. The detected AE energy level in this specimen is very low during the test followed by a sudden release of energy at the moment of debonding. On the other hand, the fibers slipping failure mode produces a progressive release of energy during the test while the adhesive bond diminishes, followed by a reduction of the $A E$ energy rate in the stage governed by frictional resistance. 


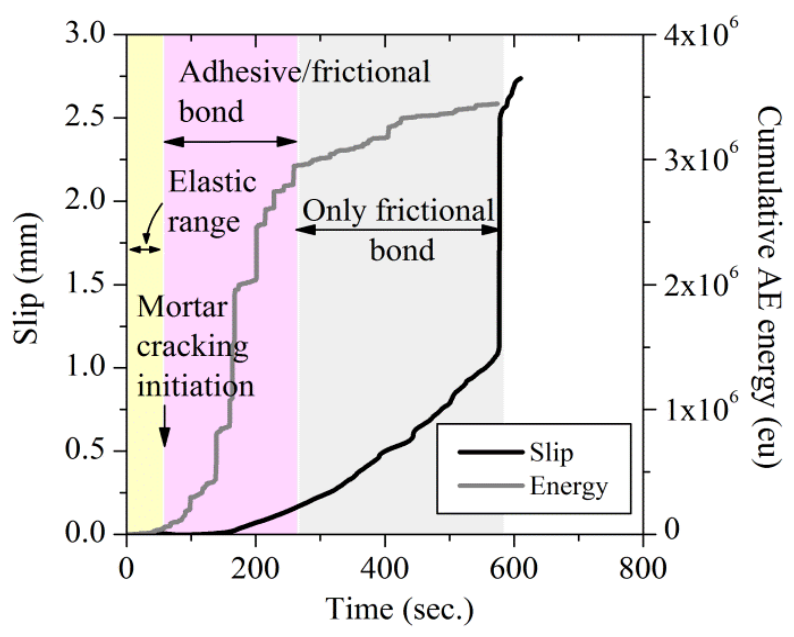

Figure 7. Typical AE results in an SRG-strengthened brick specimen: evolution of slip and cumulative $A E$ energy

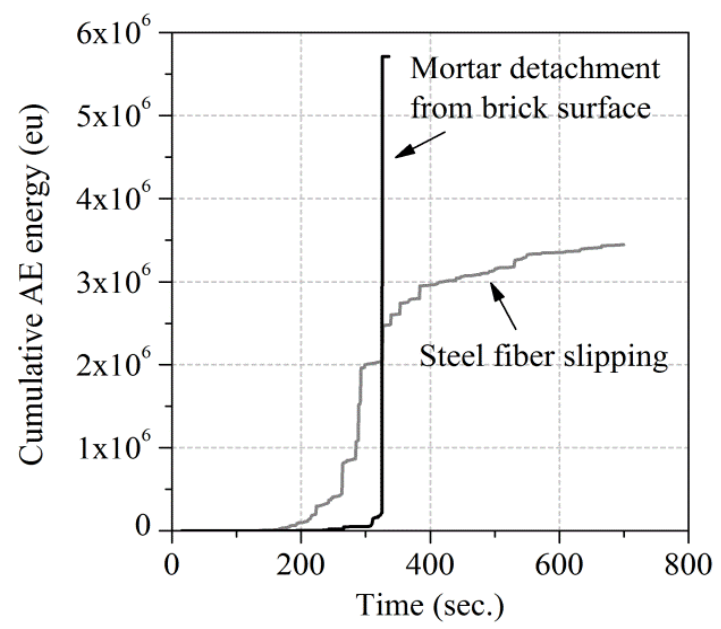

Figure 8. Comparison of AE output for different failure modes in SRG-strengthened bricks

\subsection{Location of debonding}

During the single-lap shear bond tests, AE sources were located in real time. For the SRG-strengthened specimens, very few AE sources are located due to heterogeneity of the propagation path. For the GFRPstrengthened specimens, AE source location starts with the onset of the macro-fracture range at the loaded end of the laminate and progressively moves down during the test. This is in accordance with the expected downward movement of the debonded area.

This downshift of located AE events as a function of time is illustrated in Figures 9 and 10. The moments at which the cumulated energy from the located $A E$ events is calculated, are indicated on the force-slip curves in Figure 9. The color bars in Figure 10 present the total energy of all AE events located in zones of $1 \mathrm{~cm}$ perpendicular to the loading direction. Herein, interval 1 refers to the time duration between the start of the test and point $A$ on the force-slip curve, interval 2 spans the time duration between point $A$ and $B$, etc.. The $Y$-axis indicates the vertical distance between the $A E$ sensors $(12 \mathrm{~cm})$. 
Progressive debonding can more distinctively be observed for the specimen with predominantly cohesive debonding (=progressive cohesive/adhesive debonding) and the cohesive debonding phenomenon typically produces more and higher-energy AE sources.

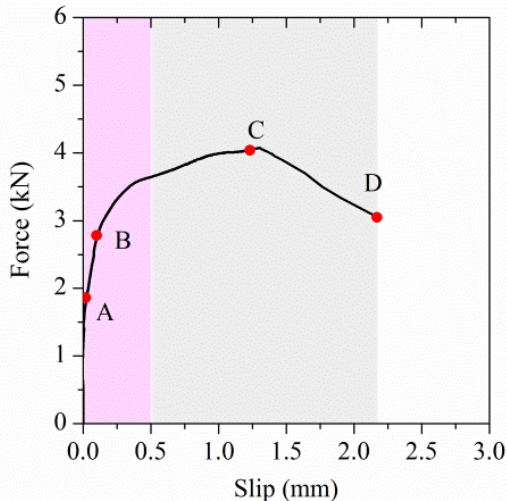

(a)

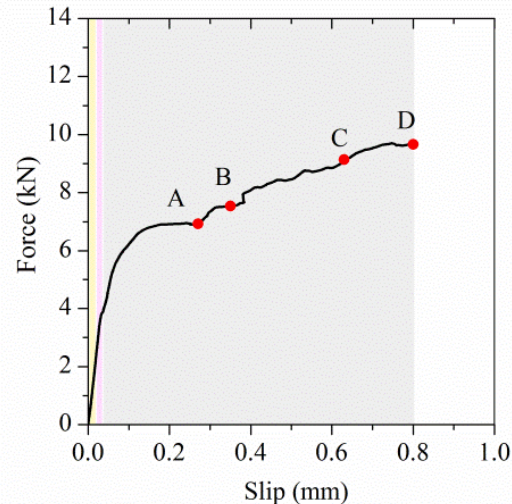

(b)

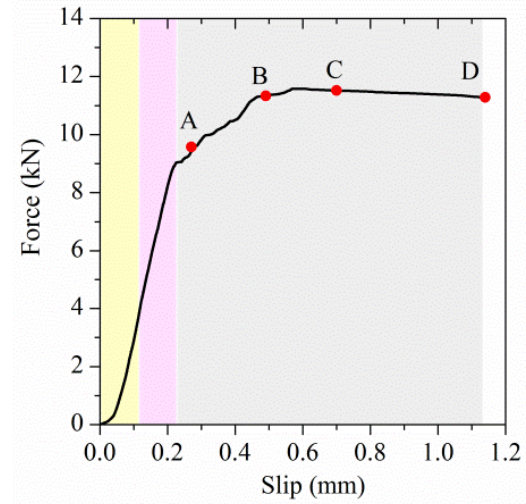

(c)

Figure 9. Force-slip curves of representative specimens for $A E$ event location analysis. Time intervals 1 to 4 in Figure 10 refer to the moments (start of the test $-A-B-C-D$ ) indicated on the force-slip curves.

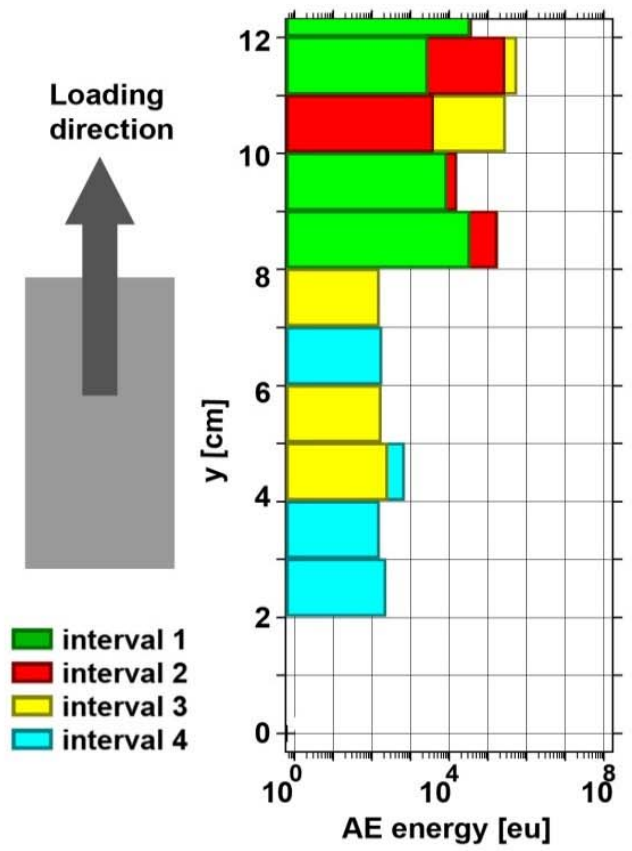

(a)

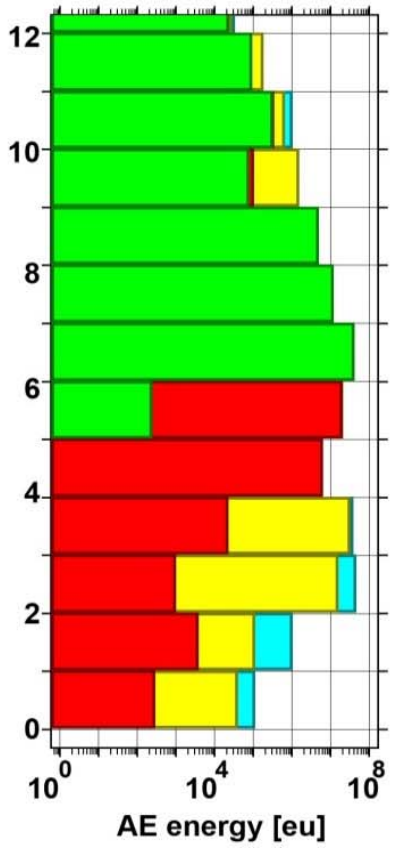

(b)

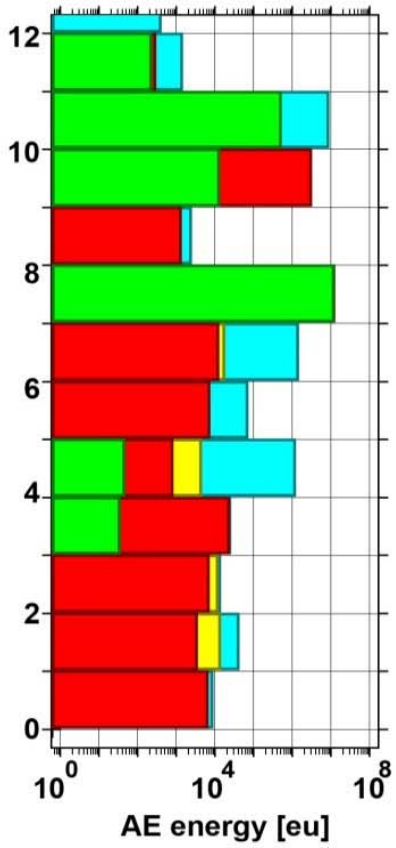

(c)

Figure 10. Cumulated energy of located AE events on SRG-strengthened specimen (a), GFRPstrengthened specimen with progressive cohesive/adhesive debonding (b) and with predominantly adhesive debonding (c). 


\section{QUALITATIVE COMPARISON WITH OTHER NDT BASED ON LITERATURE DATA}

A qualitative comparison is presented in this section between the acoustic emission technique, digital image correlation and IR thermography. DIC and IR thermography were applied on specimens similar to the ones presented in this study $[15,16]$.

DIC has been used during shear bond tests on GFRP- and SRG-strengthened bricks to obtain the evolution of strains on the FRP surface, see Figure 11. The obtained full-field distribution of strains can be used to investigate the three-dimensional nature of the bond behavior, effective bond length, transversal strains and also extracting or validating the bond-slip laws. The surface strains are due to the cumulative effect of all active fracture mechanisms during the debonding and, therefore, failure or fracture modes cannot be recognized from the DIC outputs. Damage initiation and interfacial microcracking cannot be exactly detected, while FRP debonded areas can be monitored and located during the tests from the obtained strain distribution. In SRG-strengthened specimens, the crack evolution on the mortar surface can be precisely followed during the debonding tests [15]. For on-site application, this technique could be used for short- or medium-term investigations when the FRP surface is visible and accessible and the speckle patter is protected from degradation.

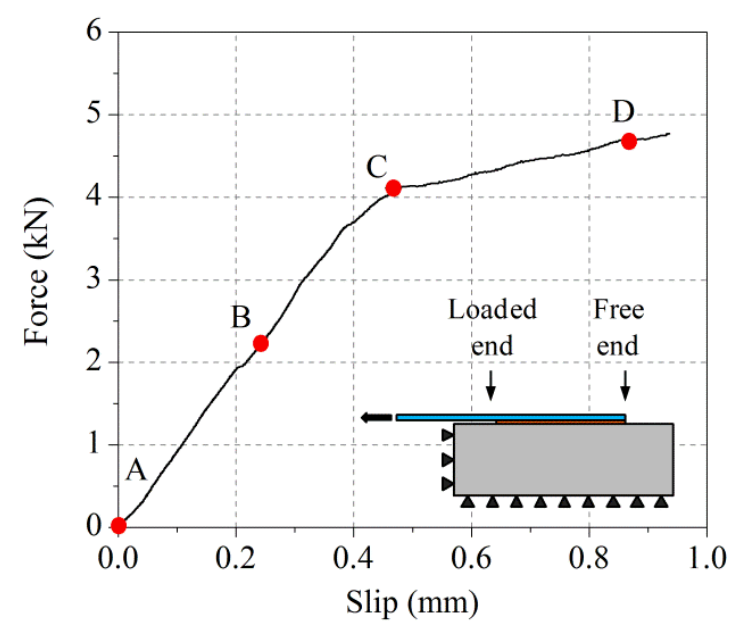

(a)

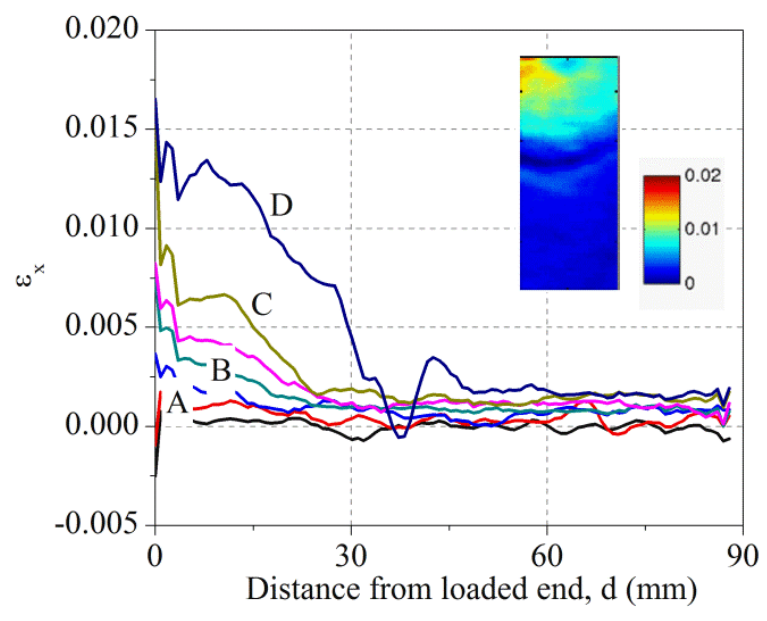

(b)

Figure 11. Application of DIC in shear bond tests: (a) force-displacement behavior of a GFRPstrengthened brick specimen; (b) longitudinal strains along the centroid and obtained full-field strain distribution at point $D$.

The use of active IR thermography for detection of interfacial flaws and FRP delamination induced by environmental ageing, with specimens similar to the ones used in this study, is reported in [16]. It was shown that this method could effectively follow the debonding, although further research is required for standardization of the procedure. For detection of the interfacial flaws, it was observed that FRP 
delaminations larger than $5 \mathrm{~mm}$ can be detected and their size measured precisely. Moreover, the technique was successfully used for detection of FRP delamination induced by accelerated ageing, see Figure 12. The output of this technique is the full-field surface temperature in which the cold or hot spots, depending on the heat excitation method, represent interfacial defects or delamination. Similar to DIC, the failure mode cannot be recognized from the outputs. A drawback of IR thermography is that any changes in the material thermal properties, which may not be necessarily due to the FRP delamination or defects, are observed as hot/cold spots in the thermograms. For instance, the nonuniformity of the FRP surface in wet lay-up applications may result in misleading interpretation of the results. For on-site application, this technique is also limited to the cases in which the FRP surface is accessible and not protected with renderings. The accuracy of the results is also dependent on the uniformity of the surface heating which is a complex task when the observation is performed on a large structural element.

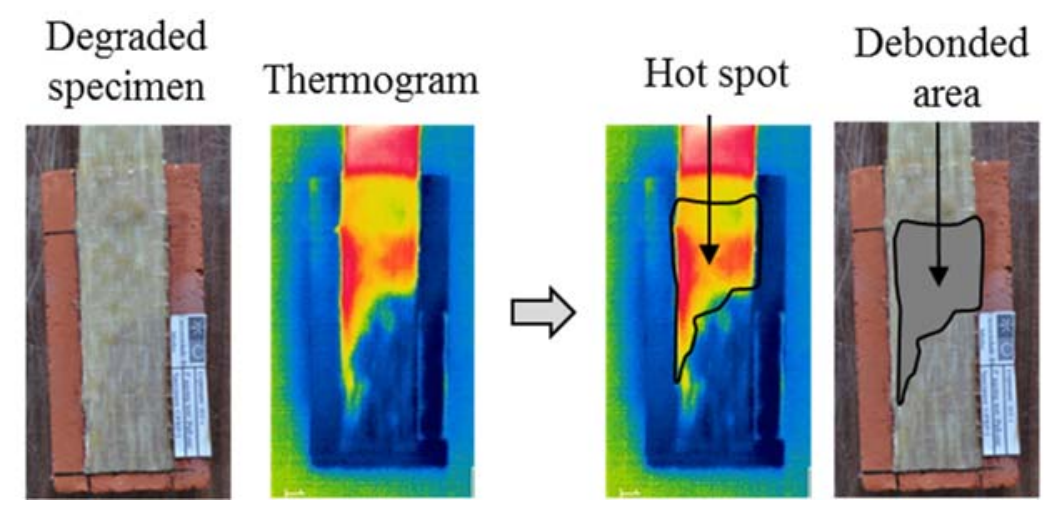

Figure 12. Application of IR thermography in detection of FRP delaminations.

Table 2 summarizes the discussed advantages and limitations of each method and compares them with the acoustic emission technique. The term semi-3D damage detection is applied when flaws can be detected in depth, but the depth is restricted to a few $\mathrm{mm}$ from the surface.

Table 2 Comparison of AE, DIC and IR thermography methods.

\begin{tabular}{lll} 
Acoustic emission technique $\quad$ Digital image correlation $\quad$ IR thermography \\
\hline
\end{tabular}

Full-field (3D)

Full-field (semi-3D)

Full-field (semi-3D)

Contact inspection

Non-contact inspection

Non-contact inspection 


\begin{tabular}{|c|c|c|}
\hline $\begin{array}{l}\text { Measures elastic waves induced } \\
\text { by the fracture process }\end{array}$ & Measures surface deformations & Measures surface temperature \\
\hline $\begin{array}{l}\text { Qualitative and quantitative } \\
\text { analysis }\end{array}$ & $\begin{array}{l}\text { Qualitative and quantitative } \\
\text { analysis }\end{array}$ & $\begin{array}{l}\text { Qualitative and quantitative } \\
\text { analysis }\end{array}$ \\
\hline $\begin{array}{l}\text { Fracture mechanism can be } \\
\text { characterized }\end{array}$ & $\begin{array}{l}\text { Fracture mechanism cannot be } \\
\text { characterized }\end{array}$ & $\begin{array}{l}\text { Fracture mechanism cannot be } \\
\text { characterized }\end{array}$ \\
\hline $\begin{array}{l}\text { Localization of the fracture, } \\
\text { limited location accuracy }\end{array}$ & $\begin{array}{l}\text { Localization of the debonded } \\
\text { areas }\end{array}$ & $\begin{array}{l}\text { Localization of the debonded } \\
\text { areas }\end{array}$ \\
\hline $\begin{array}{l}\text { Detection of FRP delamination or } \\
\text { interfacial defects is possible if } \\
\text { the sensors are attached to the } \\
\text { specimens before occurrence of } \\
\text { the delamination }\end{array}$ & $\begin{array}{l}\text { Detection of FRP delamination or } \\
\text { interfacial defects is possible if } \\
\text { digital imaging is performed } \\
\text { before and after occurrence of } \\
\text { the flaw }\end{array}$ & $\begin{array}{l}\text { FRP delamination or interfacial } \\
\text { defects can be detected at any } \\
\text { time }\end{array}$ \\
\hline $\begin{array}{l}\text { Access to FRP surface is needed, } \\
\text { sensor can be integrated, remote } \\
\text { sensing is possible }\end{array}$ & $\begin{array}{l}\text { Access to the FRP surface is } \\
\text { required, remote sensing is } \\
\text { difficult }\end{array}$ & $\begin{array}{l}\text { Access to the FRP surface is } \\
\text { required, remote sensing is not } \\
\text { possible }\end{array}$ \\
\hline
\end{tabular}

\section{CONCLUSIONS}

Acoustic emission data obtained during the accelerated ageing test demonstrated the thermal incompatibility between the clay bricks and epoxy-bonded FRP composite, since AE hits were predominantly detected during temperature decrease for the GFRP-strengthened brick specimens. This conclusion strengthens the general consensus that besides epoxy-based systems, new strengthening techniques should be developed with better mechanical and thermal compatibility with the masonry substrate.

During the experimental shear bond tests, debonding damage was successfully detected, characterized and located, although location accuracy is limited due to the relative dimensions of the applied setup. In addition, a qualitative comparison was made between debonding detection with the AE technique, IR thermography and digital image correlation technique, in which the first showed advantages for on-site long-term bond quality monitoring.

\section{ACKNOWLEDGEMENTS}

The authors acknowledge the financial support of the Research Foundation - Flanders (FWO) for the mobility grant offered to Els Verstrynge. 


\section{REFERENCES}

1. Aiello, M.A., F. Micelli, and L. Valente, Structural upgrading of masonry columns by using composite reinforcements. Journal of Composites for Construction, 2007. 11(6): p. 650-658.

2. Corradi, M., A. Grazini, and A. Borri, Confinement of brick masonry columns with CFRP materials. Composites Science and Technology, 2007. 67(9): p. 1772-1783.

3. Fédération international du béton (fib), Externally bonded FRP reinforcement for $R C$ structures, Technical Report bulletin 14, CEB-FIP, Editor 2001.

4. Borri, A., G. Castori, and M. Corradi, Intrados strengthening of brick masonry arches with composite materials. Composites Part B: Engineering, 2011. 42(5): p. 1164-1172.

5. Valluzzi, M.R., C. Modena, and G. de Felice, Current practice and open issues in strengthening historical buildings with composites. Materials and Structures, 2014. 47(12): p. 1971-1985.

6. Garmendia, L., et al., Strengthening masonry vaults with organic and inorganic composites: An experimental approach. Materials \& Design, 2015. 85: p. 102-114.

7. Valluzzi, M.R., et al., Round robin test for composite-to-brick shear bond characterization. Materials and Structures, 2012. 45(12): p. 1761-1791.

8. ICOMOS, ICOMOS Charter - Principles for the analysis, conservation and structural restoration of architectural heritage, www.icomos.org. 2003.

9. de Felice, G., et al., Mortar-based systems for externally bonded strengthening of masonry. Materials and Structures, 2014. 47(12): p. 2021-2037.

10. Wan, B., M.F. Petrou, and K.A. Harries, The Effect of the Presence of Water on the Durability of Bond between CFRP and Concrete. Journal of Reinforced Plastics and Composites, 2006. 25(8): p. 875-890.

11. Ghorbani, R., F. Matta, and M.A. Sutton, Full-Field Deformation Measurement and Crack Mapping on Confined Masonry Walls Using Digital Image Correlation. Experimental Mechanics, 2015. 55(1): p. 227-243.

12. Lai, W.L., et al., Characterization of Flaws Embedded in Externally Bonded CFRP on Concrete Beams by Infrared Thermography and Shearography. Journal of Nondestructive Evaluation, 2009. 28(1): p. 27-35.

13. Mahmoud, A.M., et al., Non-destructive ultrasonic evaluation of CFRP-concrete specimens subjected to accelerated aging conditions. NDT \& E International, 2010. 43(7): p. 635-41.

14. Taillade, F., et al., Shearography and pulsed stimulated infrared thermography applied to a nondestructive evaluation of FRP strengthening systems bonded on concrete structures. Construction and Building Materials, 2011. 25(2): p. 568-574.

15. Ghiassi, B., et al., Application of digital image correlation in investigating the bond between FRP and masonry. Compos struct, 2013. 106: p. 340-349.

16. Ghiassi, B., et al., Assessment of the bond quality degradation in FRP-strengthened masonry using IR thermography technique in FRPRCS112013: Guimaraes, Portugal.

17. Aggelis, D.G., et al., Acoustic emission characterization of the fracture process in fibre reinforced concrete. Construction and Building Materials, 2011. 25(11): p. 4126-4131.

18. Ohno, K. and M. Ohtsu, Crack classification in concrete based on acoustic emission. Construction and Building Materials, 2010. 24(12): p. 2339-2346.

19. Wevers, M., Listening to the sound of materials: Acoustic emission for the analysis of material behaviour. NDT \& E International, 1997. 30(2): p. 99-106.

20. Lockner, D. and J. Byerlee, Acoustic Emission and Creep in Rock at High Confining Pressure and Differential Stress. Bulletin of the Seismological Society of America, 1977. 67(2): p. 247-258.

21. Grosse, C.U. and M. Ohtsu, eds. Acoustic emission testing - basics for research - applications in civil engineering. 2008, Springer. 
22. Verstrynge, E., et al., Monitoring and predicting masonry's creep failure with the acoustic emission technique. NDT \& E International, 2009. 42(6): p. 518-523.

23. Tomor, A.K. and E. Verstrynge, $A$ joint fatigue-creep deterioration model for masonry with acoustic emission based damage assessment. Construction and Building Materials, 2013. 43: p. 575-588.

24. Anzani, A., et al., Evaluation of the repair on multiple leaf stone masonry by acoustic emission. Materials and Structures, 2008. 41(6): p. 1169-1189.

25. Carpinteri, A., G. Lacidogna, and M. Paggi, Acoustic emission monitoring and numerical modeling of FRP delamination in RC beams with non-rectangular cross-section. Materials and Structures, 2007. 40(6): p. 553-566.

26. Degala, S., et al., Acoustic emission monitoring of CFRP reinforced concrete slabs. Construction and Building Materials, 2009. 23(5): p. 2016-2026.

27. Masera, D., P. Bocca, and A. Grazzini, Frequency Analysis of Acoustic Emission Signal to Monitor Damage Evolution in Masonry Structures. 9th International Conference on Damage Assessment of Structures (Damas 2011), 2011. 305. 